\title{
Algumas considerações sobre 0 ensino do sistema de numeração: discussão de atividades à luz da conceitualização e representação semiótica
}

\author{
Celia Finck Brandt \\ Méricles Thadeu Moretti*
}

\section{Resumo}

Este trabalho apresenta os resultados de um estudo que se voltou para reflexões sobre a organização do processo de ensino e aprendizagem da estrutura do sistema de numeração decimal presente nos registros de representação do número, expressos tanto por um numeral arábico quanto por uma palavra. Busca-se compreender a atribuição de significação para as reservas em operações (vai um, empresta um) e a identificação do valor relativo dos algarismos da representação arábica, que depende da posição ocupada pelo algarismo no numeral. Procura-se, ainda, estudar a conexão entre os algarismos como grupos de potências de dez, de acordo com a posição no numeral, e os sufixos e prefixos, também, como grupos de potências de dez na palavra. Este trabalho encontra sustentação na noção de não congruência semântica e nas operações de tratamento e conversão no âmbito da teoria dos registros de representação semiótica, desenvolvida por R. Duval.

Palavras-chave: Registros de representação semiótica. Representação versus conceitualização. Sistema de numeração decimal.

\section{Introdução}

Este estudo contempla a investigação dos aspectos importantes a serem levados em conta na organização de atividades propostas em situação de ensino, voltadas para a aprendizagem da estrutura do sistema de numeração decimal (SND).

As reflexões consideram alguns resultados de pesquisa (KAMII; JOSEPH, 1992; KAMII; LIVINGSTON, 1995, KAMII; DECLARK, 1996; TEIXEIRA, 1996; BRANDT, 2005) que apontam dificuldades apresentadas pelas crianças para identificar a estrutura do SND nos numerais arábicos e que estão na base de outras, tais como: 
- a não atribuição de significação para as reservas em operações de adição e subtração (vai um, empresta um). Por exemplo, o aluno não sabe por que o "um" que empresta se transforma em 10 e diz que “o 'um' emprestado vale 'um' mesmo; que a soma resultante de uma adição maior do que dez deixa o algarismo que excede a 10 embaixo e vai 'um', pois é assim que tem que fazer";

- a não identificação do valor relativo dos algarismos da representação arábica (que depende da posição ocupada pelo algarismo no numeral). Por exemplo, o aluno circula um e cinco objetos para os algarismos 1 e 5 do numeral 15 (ou primeiro e quinto);

- a realização, de forma mecanizada, das operações com utilização de algoritmos, caracterizada pela memorização de procedimentos e passos que não se fazem acompanhar de interpretações ou de explicações dos porquês.

Partiu-se do pressuposto de que a dificuldade de justificar, com fundamentos, os procedimentos utilizados para a realização de operações está relacionada ao não reconhecimento da estrutura do SND nos registros de representação do número, independentemente de tal registro ser um numeral arábico ou uma palavra.

No caso do numeral arábico, os algarismos não são nem identificados como grupos de potências de dez, de acordo com a posição, nem conectados por meio de adições e multiplicações, como, por exemplo, $333=3 \times 100+3 \times 10+3$, nos diversos valores posicionais do 3 .

No caso da palavra, os sufixos e prefixos, também, não são nem identificados como grupos de potências de dez, nem articulados entre si por meio de adições e multiplicações. Por exemplo: na palavra "quarenta", o prefixo "quar" representa quatro e o sufixo "enta" representa uma dezena (ou uma potência de 10), sendo articulados por meio da multiplicação $4 \times 10$.

$\mathrm{O}$ estudo abrangeu a investigação dos aspectos importantes a serem contemplados na organização de atividades para serem propostas em situação de ensino, voltadas para a aprendizagem da estrutura do SND. Levou-se em consideração que os números são, mais usualmente, representados por numerais ou palavras, motivo pelo qual se buscou sustentação numa teoria de representações semióticas. Essa escolha se justifica em virtude dos argumentos apresentados por Duval, a seguir transcritos:

[...] o problema da aprendizagem [...] deve ser formulado não em termos do funcionamento cognitivo do sujeito, mas [...] em termos de condições de compreensão. [...] que não estão ligadas a um conteúdo particular, mas à natureza das atividades e dos raciocínios que se encontram exigidos através de diferentes conteúdos ensinados (1996, p. 377). 
Essa teoria vai permitir que sejam caracterizados, nas atividades, os raciocínios específicos e as operações cognitivas de formação, tratamento e conversão a serem propostas quando o sujeito interage com registros de representação do número (palavra e numeral arábico) para a aprendizagem da estrutura do SND (base e valor posicional) veiculada nesses registros. A operação cognitiva de formação se refere à elaboração de registros de representação para os números e, para isso, à utilização, por exemplo, de palavras ou numerais, dentre outros. A operação cognitiva de tratamento concerne à transformação do registro de representação no interior de um mesmo sistema semiótico, como, por exemplo, $21=2 \times 10+1$. A operação cognitiva de conversão, também, se refere a uma transformação de um registro de representação, pertencente a um sistema semiótico, em outro, pertencente a outro sistema semiótico, como, por exemplo, converter "31" em "trinta e um".

A teoria de representações semióticas constitui um aporte teórico para a organização das atividades, voltada para o aprendizado do conteúdo dos registros de representação do número, isto é, para o aprendizado do padrão de organização da palavra e da escrita arábica que veiculam a estrutura do SND e o aprendizado dessa estrutura.

Por exemplo: nas palavras, essa estrutura, em virtude de seu padrão de organização, se apresenta nos prefixos e sufixos, que são articulados entre si por operações de adição e multiplicação, como os numerais "onze" e "quarenta e dois":

\begin{tabular}{|l|l|}
\hline \multicolumn{1}{|c|}{ Palavra } & \multicolumn{1}{c|}{ Onze } \\
\hline $\begin{array}{l}\text { Prefixo } \\
\text { Sufixo }\end{array}$ & $\begin{array}{l}\text { on (deformação do um) } \\
\text { Le (deformação do dez) } \\
\text { Logo }\end{array}$ \\
\hline
\end{tabular}

\begin{tabular}{|l|l|}
\hline \multicolumn{1}{|c|}{ Palavras } & \multicolumn{1}{c|}{ Quarenta e dois } \\
\hline $\begin{array}{l}\text { Prefixo da palavra quarenta } \\
\text { Sufixo da palavra quarenta }\end{array}$ & $\begin{array}{l}\text { quar (deformação do quatro) } \\
\text { enta (deformação do dez) } \\
\text { Quarenta }\end{array}$ \\
$\begin{array}{l}=4 \times 10 \\
\text { Quarenta e dois }\end{array}$ & $4 \times 10+2$ \\
\hline
\end{tabular}

Nos numerais arábicos, essa estrutura, devido ao seu padrão de organização, se apresenta na posição ocupada pelos algarismos desses numerais; isto é, cada algarismo representa uma multiplicação por uma determinada potência de 10 (10, dezenas, $10^{2}=100$, centenas, $10^{3}=1000$, milhares etc.), e os resultados dessas multiplicações (os produtos) são adicionados. Por exemplo, 


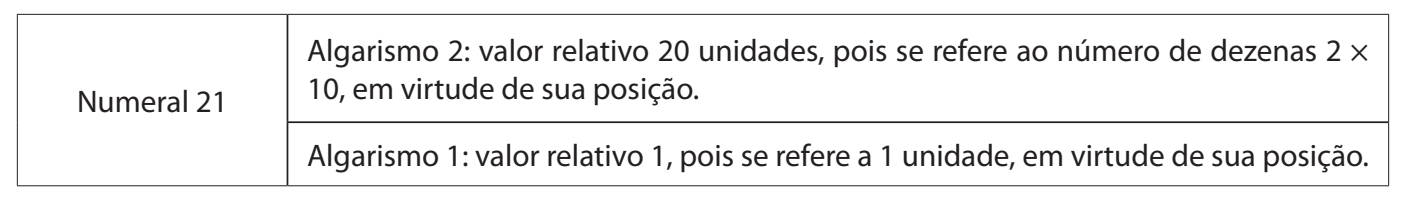

A organização das atividades considerará os procedimentos metodológicos, necessários e específicos que caracterizam a operação cognitiva de conversão de um registro de representação (palavra em numeral ou numeral em palavra). Tal organização vai permitir enfrentar o fenômeno da congruência semântica existente entre a palavra e a notação arábica, enquanto registros de representação do número.

A congruência semântica, segundo Duval (1995), é responsável por um maior ou menor sucesso na realização da conversão de um registro de representação pertencente a um sistema semiótico de representação para outro. A ocorrência da congruência semântica entre dois registros de representação, pertencentes a sistemas semióticos distintos, é dependente de três condições:

- $1^{\text {a }}$ condição: existência de correspondência semântica entre unidades significantes que constituem os dois tipos de registros.

Numa palavra que representa um número, as unidades significantes são os prefixos e sufixos e, num numeral arábico, são as posições e o valor absoluto dos algarismos. A busca de uma correspondência entre essas unidades vai significar associar uma unidade significante de um registro a uma unidade significante no outro registro.

Vamos exemplificar com os registros "dezoito" e "18". Podemos corresponder o prefixo "dez" ao algarismo " 1 " do numeral " 18 " e o sufixo "oito" ao algarismo " 8 " do " 18 ":

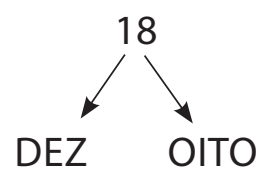

- $2^{\text {a }}$ condição: apresentação das unidades na mesma ordem nos dois registros de representação.

No exemplo em questão, as unidades significantes da palavra "dezoito" e do numeral "18" correspondem, da esquerda para a direita, em ambos os registros, à dezena e às unidades.

- $3^{a}$ condição: existência da conversão de uma unidade significante da representação de partida em uma só unidade significante na representação de chegada.

No caso da palavra "dezoito", temos as duas unidades significantes, o prefixo "dez" e o sufixo "oito", que são convertidas em outras duas, no numeral "18", isto é, 
nos algarismos " 1 " e "8", pois em ambos os registros essas unidades representam, respectivamente, a dezena e as unidades.

Isso não acontece, porém, para o registro de outros valores numéricos, como, por exemplo, o numeral arábico " 13 ” e seu associado em outro sistema semiótico, a palavra "treze":

- unidades significantes do numeral “ 13 ": “1" $\mathrm{e}$ " 3 ”, representando, respectivamente, uma dezena e três unidades;

- unidades significantes da palavra "treze": prefixo "tre" e sufixo "ze", representando, respectivamente, três unidades e uma dezena.

No caso das três condições apontadas acima, é possível verificar que as unidades significantes que se correspondem são dispostas, nos dois registros, em ordens diferentes: no numeral, o algarismo que representa a dezena é colocado à esquerda do algarismo que representa as unidades; na palavra, o prefixo, que está à esquerda, representa as unidades, e o sufixo, que está à direita, representa as dezenas. Vejamos:

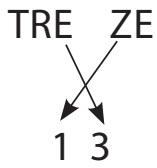

As unidades significantes não se apresentam na mesma ordem nos dois registros de representação do mesmo número, caracterizando um caso de não congruência semântica, o que contribui, de acordo com os estudos realizados por Duval (1995), para um custo cognitivo maior em relação à conceitualização dos objetos matemáticos. No caso em questão, esse fato compromete a atribuição de significados à palavra e ao numeral arábico, o que poderá implicar a não identificação da estrutura do SND veiculada nesses dois tipos de registros de representação do número.

Outros exemplos podem ilustrar casos de não congruência semântica, como no das palavras "quarenta e seis" e seu registro associado, o numeral " 46 ":

- unidades significantes do numeral " 46 ": “4" e "6", representando, respectivamente, quatro dezenas e seis unidades;

- unidades significantes das palavras "quarenta e seis": prefixo da palavra quarenta "quar" e sufixo "enta", representando quatro dezenas. Essas duas unidades, "quar" e "enta", correspondem a uma única unidade do outro registro, o algarismo 4.

Nesse caso, não existe a correspondência de duas unidades significantes de um registro a outras duas no outro registro: 


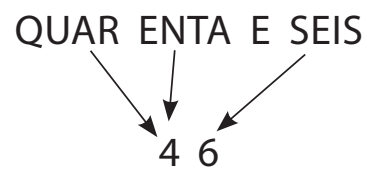

Outros valores numéricos podem ser analisados ${ }^{1}$ em relação à congruência semântica entre dois registros que os representam.

\section{Implicações para o ensino}

Os estudos de Duval sinalizam para aspectos essenciais a serem contemplados no processo de ensino, seja qual for o objeto de conhecimento foco da aprendizagem: as operações cognitivas de formação, tratamento e conversão.

Foram elaboradas diversas atividades com especificidades diferentes em relação a vários aspectos de natureza operatória contemplados na estrutura do SND. Em algumas, foram consideradas as operações cognitivas de formação, tratamento ou conversão com os registros de representação do número; em outras, certos intervalos numéricos, nos quais a não congruência semântica é acentuada por diversos fatores que comprometem a compreensão da estrutura do SND; e, na maioria delas, resultados de pesquisas considerados importantes para subsidiar as atividades elaboradas, associados às operações cognitivas que privilegiam.

Todas as atividades permitem: períodos diferenciados de trabalho em sala de aula (dependente das condições das crianças); possibilidades de acréscimos de questões ou questionamentos (dependente do diálogo que se travar no momento da realização das atividades); composição dos enunciados no momento de sua proposição ao grupo de crianças, entre outras questões. Isso posto, acrescenta-se que as atividades não constituem um receituário a ser seguido, mas antes uma proposta que procura levar em conta uma teoria de representações semióticas na organização da prática educativa voltada para a aprendizagem do SND, normalmente, não contemplada no processo de ensino desse objeto de conhecimento.

As atividades apresentadas a seguir serão acompanhadas de análises e comentários que se fazem pertinentes.

\section{Uma proposta para a aprendizagem da estrutura do SND}

As primeiras atividades organizadas podem focar a estrutura do SND nos registros de representação dos números, compreendidos no intervalo de onze a quinze. Para essas atividades, podem ser considerados os resultados da pesquisa 
realizada por Fuson e Kwon (1991), que se voltou para a atribuição de sentido quantitativo aos números expressos por algarismos e sua interpretação em termos de dezenas e unidades. Isso porque, segundo os autores, o padrão alfabético, devido às suas irregularidades, não explicita diferentes tipos de agrupamentos de dez (dezenas, centenas e outros). Por exemplo, não fica claro para uma criança que o prefixo "do" do numeral "doze" representa duas unidades e o sufixo "ze", dez unidades e, muito menos, que podemos associar esse prefixo e esse sufixo aos algarismos 2 e 1 do numeral "12", visto que, pela sua posição, o algarismo 1 representa dez unidades e o algarismo 2, duas unidades.

Fuson e Kwon (1991) apresentam, dentre outros, dois itinerários utilizados por crianças para adições cujas somas superiores a 10 podem ser expressas por: 10 $+\mathrm{x}$ ou $\left(5+\mathrm{x}_{1}\right)+\left(5+\mathrm{x}_{2}\right)$ como, por exemplo:

$$
8+9=17=10+7 \text { ou } 8+9=17=(5+3)+(5+4)=10+(3+4)=10+7
$$

Os itinerários estudados são, conforme os autores, mais favoráveis aos métodos de cálculo dessas adições com somas estruturadas em torno de 10, por envolverem um procedimento que chama a atenção para as palavras e a escrita arábica, que não trazem explicitada essa formação em torno de 10.

Esses dois itinerários podem ser contemplados em duas atividades diferentes, para adições de valores, com somas situadas no intervalo de 11 a 19, com utilização das mãos.

O itinerário 1, inserido numa das atividades, pode compreender o seguinte procedimento:

- colocar a primeira parcela da adição numa das mãos, levantando os dedos, a partir do dedinho, e, na sequência, seguindo para a segunda mão, colocar uma parte da segunda parcela que, por esse motivo, fica decomposta em duas partes "a" e "b", de tal forma que a parte "a", adicionada à primeira parcela, representa o valor que permite atingir 10;

- abaixar os dedos;

- levantar os dedos novamente para colocar a parte "b", pertencente à segunda parcela, que caracteriza o valor da soma resultante que excede a 10.

$\mathrm{Na}$ exposição das mãos, podemos visualizar a operação $4+9$ realizada, em que o numeral 10 é representado por todos os dedos das mãos, abaixados: 


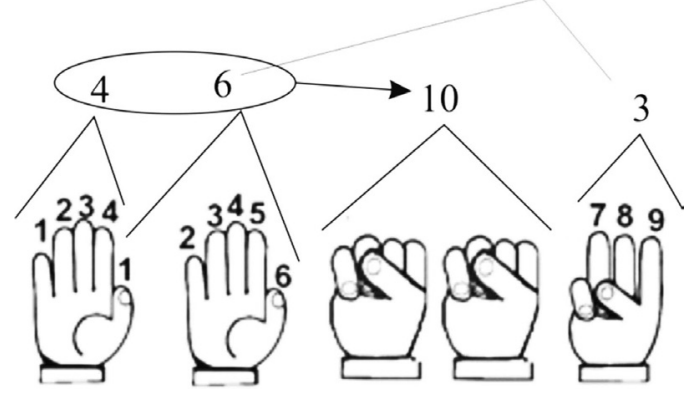

Duas transformações são mostradas nos movimentos das mãos: $4+6+3=10$ +3 , para a soma $4+9$.

$\mathrm{O}$ itinerário 2, contemplado em outra atividade, permite um procedimento diferente:

- decompor cada parcela em duas partes "a" e "b" e "a" e "b", sendo a = 5, (exemplo: para as parcelas 8 e 7 , a decomposição fica: $8=5+3$, portanto, a $=5$ e $\mathrm{b}=3$ e $7=5+2$; portanto, $\mathrm{a}=5$ e $\mathrm{b}_{1}=2$ );

- utilizar os dedos de uma mão para representar o valor "b" e os da outra para representar o valor " $\mathrm{b}_{1}$ ";

- anunciar a soma obtida como igual a 10 e "b" + "b" pois 10 é resultante da adição dos valores 5 presentes nas duas parcelas:

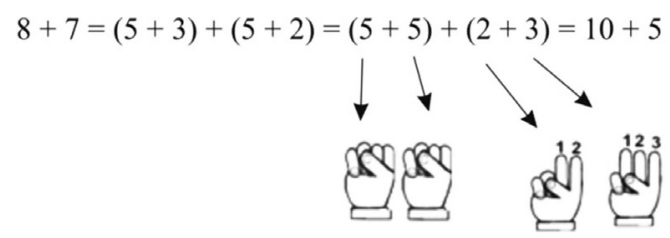

Para cada soma obtida nos dois itinerários, solicita-se a identificação do grupo de dez formado, correspondente aos dedos que ficaram abaixados, nos algarismos da representação arábica e nas partes das palavras (sufixos e prefixos).

Essas atividades contemplam a operação cognitiva de tratamento, visto que propõem uma transformação intrarregistro referente à partição de uma ou das duas parcelas dos valores numéricos envolvidos, tanto num itinerário como no outro. As transformações que ocorrem para adicionar 4 e 9, com utilização do itinerário dos dedos cardinalizados, são oportunizadas e entram em ação quando a criança, ao contar na sequência, faz a partição da segunda parcela da adição em duas partes: uma para completar 10 e outra referente ao complemento da segunda parcela. 
Elas compreendem, também, a operação cognitiva de conversão, ao explicitar os agrupamentos em torno de 10 e ao propor a interpretação e identificação desses agrupamentos, na palavra (sufixos e prefixos) e na escrita arábica (com a atribuição do valor relativo ao algarismo do numeral), em virtude de seus padrões de organização: soma anunciada em termos dos dez dedos abaixados e dos que restaram em pé, 10 e $\mathbf{x}$, e sua associação à palavra xze e à escrita arábica $1 \mathbf{x}$. Tal operação é consolidada quando se realiza uma análise das palavras $\mathbf{x}$ e dez, bem como de suas deformações, que possibilitam a identificação das dez unidades no sufixo "ze" da palavra xze e no algarismo 1 da representação arábica $1 \mathbf{x}$. No exemplo em questão, utilizado para ilustração, tem-se 10 e 3, a palavra "treze" e a escrita arábica "13", além das deformações: três - tre; dez - ze.

A atividade cognitiva de conversão exige, por sua vez, certos procedimentos para não ficar no patamar de simples decodificação. Segundo Duval (1995), ela não é trivial nem cognitivamente neutra, pois haverá uma operação cognitiva que pode ser descrita como uma mudança de forma.

A mudança de forma é importante, na medida em que permite que se utilizem diferentes registros de representação para um mesmo objeto matemático, além de contemplar outras vantagens:

- a economia que se apresenta quando uma representação supera os limites de outra, ou permite que certas relações sejam mais rapidamente identificadas (entre objetos ou nos próprios objetos);

- e a complementaridade de registros, por compreender os elementos informativos ou comunicacionais que a representação torna possível.

A notação arábica possibilita o tratamento algoritmo, como, por exemplo, em $12+13$. No entanto, a palavra é capaz de explicitar melhor, por vezes, a estrutura do SND, como, por exemplo, a palavra "dezesseis".

Os itinerários propostos para as adições, nas duas atividades, compreendem a explicitação do sentido quantitativo, tanto na notação arábica quanto na palavra, visto que é possível a interpretação do grupo de dez (dezena) formado e das unidades que excedem a dez, tanto nos algarismos justapostos do numeral como nos sufixos e prefixos da palavra. Abrangem, igualmente, a possibilidade de enfrentar o fenômeno da não congruência existente entre palavra e notação arábica, muito forte no intervalo numérico de onze a quinze, e que dificulta a identificação da estrutura do SND presente nesses dois registros de representação do número.

A realização das duas atividades vai compreender procedimentos que evidenciarão a distinção dos diversos níveis de articulação de sentido atribuídos aos registros de representação. Isso porque, para descrever a soma obtida em duas partes, $10+\mathrm{b}$, de acordo com itinerário 1 , ou $10+\left(\mathrm{b}+\mathrm{b}_{1}\right)$, de acordo com o itinerário 2 será 
necessária a articulação dessas partes com os registros de representação utilizados para anunciá-las: no caso da palavra escrita, elas devem ser identificadas nos prefixos e sufixos; e, no caso da escrita arábica, devem ser identificadas nos algarismos do numeral conforme a sua posição, a atribuição de sentido cardinal e ordinal aos dedos e o estabelecimento de sua correspondência aos registros de representação.

Para a elaboração de outras atividades, podem ser considerados alguns resultados da pesquisa realizada por Lerner e Sadovsky (1996), especificamente os que dizem respeito à explicitação da estrutura do SND identificada em hipóteses estabelecidas por crianças quando comparam e ordenam valores numéricos. Duas dessas hipóteses se baseiam em critérios vinculados a uma lógica, de modo a revelar, de uma forma ou de outra, a estrutura do SND:

- Hipótese 1 - o primeiro é quem manda. Nessa hipótese, a criança afirma ser maior o numeral que possui o primeiro algarismo, da esquerda, maior, no caso de os numerais apresentarem o mesmo número de algarismos;

- Hipótese 2 - a maior quantidade de algarismos. Nessa hipótese, ao comparar dois números, a criança diz ser maior aquele que é representado pelo numeral com maior quantidade de algarismos.

Levando em consideração esses resultados, atividades que proponham comparações e/ou ordenações podem ser organizadas:

a) Primeira atividade. Propor a comparação de pares de valores numéricos (representados por numerais arábicos) e a apresentação de justificativas a respeito da superioridade do número representado pelo numeral, precedidas de alguns questionamentos ou não exemplos, dentre os quais os seguintes:

1. Outra criança me disse que um número é maior se tiver mais algarismos. Isso é sempre válido?

2. O que acontece se acrescentarmos um zero à esquerda do numeral? E se acrescentarmos um zero à direita?

3. Quando dois números, representados por numerais com a mesma quantidade de algarismos, são diferentes em um ou em dois desses algarismos, quem determina a maioridade? (Verifique a conclusão com os seguintes numerais: 425 e 325,53 e 43,57 e 59,432 e 422,432 e 423 ).

4. Quantos grupos de cem tem cada um dos numerais: $342,567,254$ e 109 ? Quantos grupos de 10 tem cada um dos numerais: 45, 39, 98, 100, 109, 117, $142,200,207,215$ e 234 ?

b) Segunda atividade. Propor a formação de numerais com três ou quatro algarismos e a ordenação dos numerais construídos, juntamente com os seguintes questionamentos: 
1. Por que um determinado numeral é maior que outro?

2. Qual dos algarismos permite identificar o maior numeral?

3. Que tipos de grupos definem um determinado algarismo de um numeral?

4. Quantos grupos de 10 são determinados por um dado algarismo de um numeral?

5. Qual algarismo permite determinar se um numeral do tipo abc (sendo a, b e c números naturais) é maior ou menor que acb: o algarismo da esquerda, o algarismo do meio ou o algarismo da direita?

6. O que significa um determinado algarismo de um numeral? Que tipos de grupos ele define?

7. Quantas centenas, dezenas e unidades possui o numeral formado?

c) Terceira atividade. Propor a inserção, por justaposição, de um algarismo num numeral de dois algarismos, em diferentes posições (por exemplo, inserir um algarismo "c" num numeral do tipo "ab", em diferentes posições), de modo que o numeral formado seja o maior possível, mediante os procedimentos a seguir:

1. a identificação do tipo de grupo representado pelo algarismo inserido conforme sua posição no numeral;

2. a comparação entre os valores numéricos representados pelos diferentes numerais formados após a inserção do algarismo tanto à direita como à esquerda ou no meio;

3. inclusão do zero para sua intercalação em um numeral com 2 algarismos e em um numeral com 3 algarismos;

4. uma generalização a respeito do zero.

Essas três atividades, em se tratando de uma teoria de representações, compreendem a operação cognitiva de tratamento. Isso porque a comparação pode exigir a decomposição do numeral da escrita arábica em suas partes constituintes e a transformação (no interior do mesmo sistema semiótico) dos algarismos do numeral, de acordo com seu valor relativo, para sustentar os argumentos a favor da superioridade de um numeral ab em relação a um numeral cb, ou de um numeral abc em relação a um numeral acb. Por exemplo:

$\mathrm{ab}$ em a dezenas $+\mathrm{b}$ unidades e cb em $\mathrm{c}$ dezenas $+\mathrm{b}$ unidades;

$a b c$ em $10^{2} a+10 b+c$ e acb em $10^{2} a+10 c+b ;$ ou

acb em $\mathbf{a}$ centenas $+\mathbf{c}$ dezenas $+\mathbf{b}$ unidades;

cab em $\mathbf{c}$ centenas $+\mathbf{a}$ dezenas $+\mathbf{b}$ unidades;

abc em $\mathbf{a}$ centenas $+\mathbf{b}$ dezenas $+\mathbf{c}$ unidades. 
Essa decomposição - e consequente transformação - tornará possível efetuar a comparação e a ordenação, contribuindo para a identificação do padrão de organização da escrita arábica: posição do algarismo no numeral e caráter operatório.

As atividades de formação de um numeral e a inserção de um algarismo, por justaposição, num numeral estão centradas nas operações cognitivas de formação de um registro.

Cabe evidenciar a importância de uma ação mediadora que conduza reflexões a respeito das regularidades identificadas, envolvendo diferentes intervalos da sequência numérica. Por essa razão, justifica-se a importância dos procedimentos e encaminhamentos propostos a seguir:

1. Em relação ao número de algarismos do numeral, pode-se conduzir a reflexão em direção ao padrão de regularidade que permitirá a associação com tipos de grupos (de cem, de dez etc.) representados. Isso será necessário para testar hipóteses levantadas a favor do número de algarismos do numeral, como, por exemplo: um numeral que possuir 3 algarismos é maior que um de dois algarismos (se o numeral possuir um zero à esquerda, terá zero centenas, x dezenas, e y unidades, e, nesse caso, poderá ser menor que um numeral de dois algarismos).

2. Questionamentos podem ser propostos para contribuir com as reflexões, como, por exemplo: que tipos de grupos definem numerais com três algarismos? E com dois algarismos?

3. Para o mesmo padrão de regularidade, podem-se incluir reflexões e análises a respeito do zero, de seu papel em relação ao número de algarismos do numeral e da alteração que ele pode provocar no numeral, dependendo da posição ocupada. Isso pode ser feito, por exemplo, com alguns questionamentos, tais como: que tipos de grupos definem um numeral com dois algarismos quando inserimos um zero à direita, à esquerda e no meio?

Com essa ação mediadora, estar-se-á privilegiando a operação cognitiva de formação, pois a inserção do zero em diversas posições num numeral o transforma em outro com significados diferentes. Por exemplo: 324 é maior que 32, pois um numeral com três algarismos é maior que um numeral de dois algarismos, visto que ele possui grupos de 100. No caso de o último algarismo da esquerda ser zero, essa hipótese não se confirma: 057 é menor que 76. No entanto, se o zero for intercalado no numeral ou colocado à direita, a situação muda, visto que o numeral produzido é representativo de outro número (507 e 570, que são maiores que 76).

É possível, também, empreender esforços no sentido de ultrapassar uma forma de conceber e utilizar os numerais que representam os números, isto é, como um lugar ocupado na sequência ou como se cada quantidade fosse "nominada" sem 
seguir regras ou leis de formação, caracterizando uma lexicalização direta. A representação, com utilização da escrita arábica, pode passar a ser objeto de reflexão e observação de padrões de regularidades por meio de desafios colocados de modo a evidenciar os elementos da estrutura do SND: a posição do algarismo no numeral e a base do sistema de numeração, visto que cada posição é indicativa de um tipo de potência de dez.

Acredita-se que os procedimentos propostos para conduzir as atividades e as ações mediadoras caracterizam momentos voltados para a aprendizagem, como, por exemplo, no momento da identificação do padrão de regularidade e da sua justificação, pois exigirão que as crianças formulem perguntas para si mesmas. Ainda, a confrontação de hipóteses e argumentos próprios com o ponto de vista de outros se consolida como um caminho para que algum progresso venha a acontecer, na medida em que essas hipóteses podem ser corroboradas ou refutadas, sendo capazes de originar contradições geradoras de novas perguntas e novos processamentos. Trata-se de uma intensa interação com o objeto de conhecimento. A argumentação vai permitir que as relações estabelecidas pelas crianças, de forma intuitiva, se tornem claras ou sejam coordenadas com outros conhecimentos, levando-as a fazer descobertas que somente se revelam possíveis devido ao contexto da situação.

Também, a utilização de não exemplos para refutação de hipóteses falsas se apresenta como importante e necessária para a explicitação da estrutura do SND na escrita arábica e, principalmente, para uma atribuição de sentido ao zero nesse registro de representação. A análise ao recurso do não exemplo é decisiva, inicialmente, em virtude de que a réplica, numa discussão, constitui uma refutação de uma declaração mais abrangente e a resistência ao não exemplo, um teste de aceitabilidade para definições ou relações de implicação.

Há que se considerar, no entanto, que a produção de um não exemplo, apesar de ser importante, está sujeita a determinadas condições. $\mathrm{O}$ sujeito somente pode produzi-lo, num determinado domínio de conhecimento, dependendo da base de dados dos quais dispõe nesse domínio, ou de seu grau de familiaridade com o domínio. Vamos supor que uma criança apresente como não exemplo um numeral com um zero colocado à esquerda para a hipótese levantada por outra criança de que todo numeral de três algarismos é maior que um numeral de dois algarismos. Esse não exemplo apenas será apresentado se a criança identificar as potências de dez representadas pelos algarismos do numeral de acordo com a posição por ele ocupada.

A operação cognitiva de formação de uma representação, compreendida em diferentes atividades, permite que se afirme não se tratar de uma operação neutra, visto exigir o respeito às regras de conformidade, pois, segundo Duval (2003a, p. 13), se referem: à "determinação [...] das unidades elementares [...]; às combinações admissíveis de unidades elementares para formar unidades de nível superior 
[...]; às condições para que uma representação de ordem superior seja uma produção pertinente e completa”.

As atividades que exigem a formação de numerais representativos de números, com utilização da escrita arábica, requisitam que os algarismos do numeral sejam articulados entre si, de forma que sua posição coloca em jogo uma das combinações possíveis das unidades elementares. Tal combinação, nesse caso, diz respeito à posição dos algarismos no numeral que é determinante para a constituição de um novo valor representado. Assim, ao utilizar os algarismos 2, 5 e 7, pode-se formar o numeral 527, e, nesse caso, as unidades elementares foram combinadas da seguinte maneira: $5 \times 10^{2}+2 \times 10+7$. Se os mesmos algarismos fossem utilizados para formar o numeral 572, outra combinação surgiria: $5 \times 10^{2}+7 \times 10+2$.

Segundo Duval, as regras de conformidade "cumprem também uma função de identificação em um registro determinado [...]. Porém, isso não implica que o conhecimento das regras seja suficiente para a compreensão ou exploração das representações dadas" (2003a, p. 14). Por essas razões, é a ordenação dos números produzidos que possibilita colocar em evidência a estrutura do SND, no que diz respeito ao valor posicional e à base.

A produção de numerais com os três algarismos e a mudança da posição dos algarismos no numeral, provocada pela inserção, por justaposição, de um novo algarismo (por exemplo, inserir o algarismo 2 no numeral 43, de modo a obter o maior numeral possível de três algarismos) permitem que eles sejam identificados como diferentes uns dos outros e que sejam ordenados segundo critérios que se tornam explicitados com base nas justificativas apresentadas. A produção, seguida de interpretação, apela, também, para os critérios que fundamentam a ordenação, tornando necessário refletir sobre o valor relativo das unidades, de acordo com a sua posição e, ainda, sobre os tipos de grupos que representam.

Essa reflexão se volta diretamente para a organização do sistema, pelo fato de permitir que se estabeleçam as relações entre os critérios elaborados e o valor de cada algarismo em termos de grupos de 10 e de 100. É no momento da ordenação que se pode discutir sobre os critérios colocados em jogo para produzi-la e, ao mesmo tempo, questionar a validade de tais critérios e explorar as leis que regem o sistema de numeração.

Na elaboração de outras atividades, foram levados em consideração os padrões de regularidade envolvendo agrupamentos (de dez) e agrupamentos de agrupamentos (dez grupos de 10). Segundo Lerner e Sadovsky, "estabelecer regularidades cumpre um duplo objetivo: torna possível formular problemas dirigidos a explicitar a organização do sistema e permite gerar avanços no uso da numeração escrita" (1996, p. 132). Tais atividades envolvem as operações cognitivas de produção e tratamento. 
Por essa razão, organizou-se:

a) Uma atividade que propõe a alteração de preços de mercadorias em 10, 20, $30,40,100,200,300,400$ etc. reais (para mais ou para menos), na qual se solicita a identificação de padrões de regularidade. Os numerais propostos possuem dois, três e quatro algarismos.

1. Os questionamentos propostos na atividade podem se referir ao algarismo do numeral que sofrerá alteração, em virtude dos acréscimos ou das retiradas, e à sua relação com a posição por ele ocupada no numeral e com os grupos de 10 (dezenas) ou 100 (centenas) restantes, após a retirada ou o acréscimo dos grupos de 10 ou 100 unidades. Por exemplo: após alterar em 20 reais uma mercadoria de $\mathrm{R} \$ 247,00$, pode-se questionar qual algarismo sofre alteração e por que. Nesse caso, o algarismo que sofre alteração é o 4 , visto que 20 representa duas dezenas e tem que ser retirado das quatro dezenas representadas pelo algarismo 4 , devido à sua posição.

b) Uma atividade que propõe o cálculo de valores por períodos de tempo que correspondem a um número inteiro de semanas, meses, anos, entre outros. Cada período corresponderá a um número de dezenas exatas, visto que cada semana, mês ou ano corresponde a 10. Essas dezenas são acrescentadas a um valor inicial maior que dez.

1. Por exemplo: guardar dez etiquetas de embalagem de um produto por semana e calcular o número de etiquetas ao final de algumas semanas, considerando-se iniciar com quinze etiquetas.

2. Também propõe que seja calculado o número de etiquetas que tinha uma pessoa que adquiriu 85 etiquetas ao final de oito semanas.

3. A atividade propõe a apresentação de justificativas e argumentos sobre os procedimentos adotados para a obtenção do resultado.

c) Uma terceira atividade que propõe a realização de uma operação matemática que possibilite a transformação de um numeral, mantendo os demais invariantes. Essa transformação pode ser, por exemplo, zerar um dos algarismos do numeral, sendo necessário reconhecer o valor relativo do algarismo e identificar a operação de subtração como possível para responder pela transformação desejada. Posteriormente, outras transformações podem ser solicitadas. Alguns questionamentos direcionam para a especificidade da alteração:

1. O que deve ser feito para aparecer um zero no lugar dos algarismos determinados: a) no lugar do algarismo 8 do 1872; b) no lugar do algarismo 7 do 175; c) no lugar do algarismo 3 do 143.

2. Como proceder para transformar 4444 em 4440, em 4404 e em 4044. 
3. Como proceder para transformar 329 em 129, 438 em 2138, 527 em 520.

Essas atividades compreendem a operação cognitiva de tratamento, pois a proposta de operações de adição e subtração, com grupos de 10 ou de 100, vai exigir a decomposição do numeral da escrita arábica em suas partes constituintes e a transformação dos algarismos do numeral, de acordo com seu valor relativo. Essa decomposição e transformação tornarão possível efetuar a comparação, contribuindo para a identificação do padrão de organização da escrita arábica: posição do algarismo no numeral e caráter operatório.

$\mathrm{Na}$ condução dessas atividades, é necessário ressaltar a importância das ações mediadoras para possibilitar a explicitação das leis que regem o sistema de numeração e da forma como podem ser identificadas, tanto na escrita arábica quanto na escrita em língua materna. Isso ocorre porque as centenas e as unidades são mais facilmente identificadas nos algarismos do numeral que as dezenas, sem contar que nem sempre a soma de dez unidades é interpretada como um grupo de 10. Nesse caso, para aumentar dez unidades, a criança pode somar de 1 em 1, e não agrupar essas unidades, denominando-as "uma dezena", e tampouco identificar essa dezena em um dos algarismos do numeral que representa o número.

No caso da atividade que propõe acréscimos ou decréscimos de dezenas, centenas, as interferências relativas à escrita arábica devem se voltar para o tipo de grupo que dez unidades representam e sua respectiva denominação (dezena), bem como para a identificação desse tipo de grupo nesse tipo de notação. O mesmo procedimento pode ser adotado para vinte, trinta e quarenta unidades e para a identificação de dois, três e quatro grupos de 10 (ou duas, três, quatro dezenas), 100, 200, ou para a identificação de um e dois grupos de 100 (ou uma e duas 2 centenas).

Tais regularidades envolvem não somente o tipo de grupos envolvidos como também os aspectos multiplicativos envolvidos na notação numérica: três grupos de 10 equivalem a 30, o que significará alterar o dígito da casa das dezenas em três unidades (enquanto valor absoluto), que estarão significando três dezenas ou trinta unidades (enquanto valor relativo).

Por essa razão, destaca-se a importância de ações mediadoras, pois são elas que permitem que as crianças reflitam sobre a função multiplicativa do 2 , do $3 \mathrm{e}$ do 4 nas notações 20,30 e 40, como sendo $2 \times 10(10+10), 3 \times 10(10+10+10)$ ou $4 \times 10(10+10+10+10)$, respectivamente. Tal reflexão serve, também, para as centenas e, como consequência, para a organização do sistema de numeração.

Após a identificação dos padrões de regularidade, tem início a atividade de generalização, que consiste naquilo que se mantém invariante, independentemente do valor numérico trabalhado. Nesse caso, é fato que o acréscimo de dezenas ou centenas exatas somente faz alterar um dos algarismos do numeral, e esse algaris- 
mo passa a ser identificado pelo tipo de grupo que representa, de acordo com a sua posição no numeral. Na expressão de Duval,

A generalização consiste evidentemente em uma descrição da solução que não se limita mais aos dados particulares de um exemplo [...] generalizar requer que se passe num registro discursivo, pois este repousa sobre operações discursivas de designação de objetos ou, mais exatamente, sobre operações de re-designação de objetos já designados. Trata-se de transformar as referências aos objetos particulares em referências a objetos quaisquer (2003b, p. 23).

O processo, aqui, começa com uma qualificação (somente um dos algarismos do numeral altera conforme se acrescentem dezenas ou centenas exatas), e essa qualificação faz passar de um nível de designação individualizante a um nível de designação categorial, mais indeterminada, não importando se ela foi feita de uma forma explícita ou não explícita. Essa qualificação só se torna operatória se forem utilizadas letras que tornam possível a designação funcional específica às escrituras literárias. Logo, qualquer número natural que expresse a medida de um conjunto pode ser representado por um numeral (no caso da escrita arábica) do tipo $a_{n}$ $\times 10^{\mathrm{n}}+\mathrm{a}_{\mathrm{n}-1} \times 10^{\mathrm{n}-1}+\ldots .+\mathrm{a}_{1} \times 10+\mathrm{a}_{0}$, sendo $\mathrm{n}, \mathrm{a}_{\mathrm{n}}, \ldots, \mathrm{a}_{1}, \mathrm{a}_{0}$ números naturais.

Evidentemente, as crianças não chegam a esse estágio de generalização, que lança mão de atividade de descrição formal. Mas, cognitivamente, para a aprendizagem, o importante são as diferentes operações discursivas possíveis para designar um mesmo objeto.

A transformação intrarregistro presente na atividade que propõe o cálculo de 10 etiquetas por semana, adquiridas em diferentes números de semanas, coloca em evidência a estrutura do SND, o que possibilita a obtenção do número de etiquetas no prazo de 2, 3 ou 8 semanas, e essa transformação será obtida após a identificação de um padrão de regularidade. A aquisição de 10 etiquetas por semana produz um montante de 30 etiquetas, ao final de 3 semanas, e de 45 após serem adicionadas às 15 iniciais. Logo, 3 x $10=3$ dezenas leva ao acréscimo dessas 3 dezenas a 1 dezena das 15 iniciais. Isto significa que 15 tem que ser transformado em $10+5$ e 30 em 3 x 10, seguido de outra transformação, $1 d+3$ u e 3d, o que resulta, ao final de 3 semanas, 4 d +3 u e novamente a transformação $40+3=45$.

O tratamento sempre vai depender das possibilidades de funcionamento representacional do registro e, neste caso, a escrita arábica favorece o acréscimo de 3 dezenas a 1 dezena das 15 etiquetas iniciais, visto que a posição do algarismo 1 da escrita arábica revela a quantidade de grupos de 10, existentes em 15 etiquetas.

Para a organização das demais atividades, foi levado em consideração o caráter operatório, tanto da escrita por algarismos, como da língua natural.

Por esta razão uma atividade foi elaborada de modo a propor: 
a) a identificação dos tipos de grupos representados por palavras que apresentam sufixos do tipo "enta" e "centos" ou "entos" (por exemplo: nas palavras que representam os numerais 6275 e 4444);

b) a identificação da localização da posição dos algarismos nestes numerais (6275 e 4444) correspondentes às palavras com sufixo "enta" e com sufixo "centos" ou "entos"; a alteração dos prefixos das palavras precedidas de sufixos do tipo "enta" ou "entos" (centos) e a identificação do algarismo a ser alterado no numeral que representa a palavra (por exemplo, o prefixo de uma das palavras representativas do número trezentos e vinte e quatro, expresso por 324 em notação arábica, é alterado para duzentos e vinte e quatro, exigindo a alteração do algarismo correspondente na notação arábica 224).

Outra atividade, de modo a propor:

a) a identificação do número de grupos de dez nas palavras que apresentam o sufixo "enta" e o sufixo "centos" ou "entos" pela análise dos prefixos (por exemplo: quarenta representa quatro grupos de dez ou duzentos representa 2 grupos de 100); a representação de dezenas exatas expressas por palavras em algarismos arábicos e conclusão a respeito dos prefixos que precedem os sufixos "enta", em termos de operação matemática que os unem (por exemplo, sessenta em prefixo "sess", que constitui uma deformação da palavra seis, precede o sufixo "enta" e é a ele articulado por meio de uma multiplicação: 6 x 10);

b) a alteração do prefixo numa palavra com sufixo "enta" ou "entos" (centos) e a identificação da alteração provocada no numeral arábico correspondente (por exemplo, quarenta representa quatro grupos de dez e corresponde ao numeral 40, mas cinquenta representa cinco grupos de 10 e corresponderá ao numeral 50).

Uma terceira atividade, de modo a propor:

a) a explicitação das operações matemáticas que ligam os prefixos com os sufixos "enta" e com os conectivos "e" em termos de operação matemática (por exemplo, em sessenta e dois, o prefixo "sess", que constitui uma deformação da palavra seis, precede o sufixo "enta", e é a ele articulado por meio de uma multiplicação, 6 × 10, e o produto resultante, 60, articulado ao dois, por meio de uma adição, 60 + 2); a explicitação das operações contidas em números expressos por numerais arábicos (por exemplo, $245=2 \times 100+4$ x $10+5$ );

b) a alteração de prefixos nas palavras com sufixos "enta" ou "entos" (centos) e a identificação da alteração do algarismo correspondente na notação arábica e vice-versa, isto é, alteração do algarismo e identificação do prefixo a ser alterado na palavra correspondente. 
Uma quarta atividade, de modo a propor;

a) a associação entre as operações contidas nas palavras que representam os números com as operações contidas nos numerais que os representam, com explicitação dos prefixos que estão associados aos algarismos do numeral e dos sufixos que indicam a posição dos algarismos no numeral:

\begin{tabular}{c|c|c|c}
$\underline{\text { duzentos e noventa e seis }}$ & $\underline{\text { trezentos e sete }}$ & $\underline{\text { cinquenta e cinco }}$ & $\underline{\text { trinta e oito }}$ \\
\hline$\underline{296}$ & $\underline{307}$ & $\underline{55}$ & $\underline{38}$
\end{tabular}

Uma quinta atividade, de modo a propor:

a) a identificação dos sufixos e prefixos das palavras nos algarismos do numeral após a explicitação do caráter operatório da escrita; a alteração do sufixo "enta" por "entos" e do sufixo "entos" por "enta", e a conclusão a respeito das alterações provocadas na escrita arábica. Exemplos com 596:

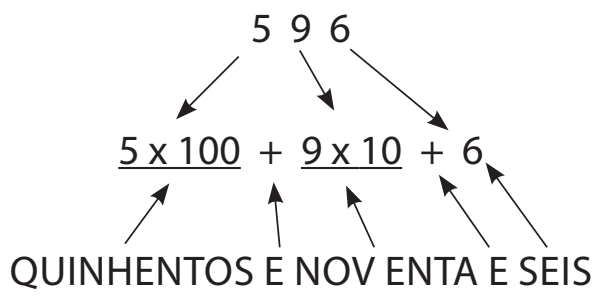

Essas atividades compreendem a operação cognitiva de conversão de acordo com uma teoria de representações, uma vez que propõem alterações nas unidades significantes nos dois tipos de registros de representação dos números: as palavras e os numerais. Nas palavras, são alterados prefixos e sufixos, e estas alterações têm que ser identificadas nos numerais correspondentes. Da mesma forma são alterados os algarismos dos numerais, e estas alterações têm que ser identificadas nas alterações de sufixos ou prefixos das palavras correspondentes. As alterações provocam o fenômeno da congruência semântica, por compreender não somente alterações de prefixos e sufixos, mas também alterações dos prefixos que precedem os sufixos. Por exemplo: ao alterar o sufixo "entos" da palavra quinhentos para "enta", será necessário trocar o prefixo "quinh" por "cinqu".

Para a análise e interpretação dessas atividades, será necessário analisar os problemas colocados pela não congruência, uma vez que compreendem uma operação de conversão. Um registro de representação A pode ser substituído por outro registro de representação $\mathrm{B}$, desde que ambos façam referência ao mesmo objeto. Porém, essa substituição não ocorre sem um determinado custo cognitivo, que é causado pelos problemas da congruência semântica. Ser referencialmente equi- 
valente não significa ser congruente. O problema da significação vem ao encontro da relação entre congruência e não congruência e pode ser responsável por certas dificuldades em matemática, cuja superação exige atenção a esse problema. Segundo Duval: "O problema da congruência ou da não congruência semântica de duas apresentações de um mesmo objeto é, portanto, o da distância cognitiva entre estas duas representações, sejam elas pertencentes ou não ao mesmo registro" (2012, p. 105).

Quanto maior a distância cognitiva, o custo de passagem de uma apresentação a outra pode aumentar, ou, também, essa passagem pode não ser efetuada ou entendida. A substitutividade se choca com dificuldades na diferença semântica. Substituir o numeral arábico pela palavra pode significar um salto entre duas redes semânticas, de tal forma que o indivíduo não o perceba, nem se for indicado a ele. Na matemática, a mudança de registro semiótico é frequente; portanto, a substitutividade desempenha papel essencial em relação ao custo cognitivo.

Conforme Duval, a não congruência semântica é uma fonte de dificuldades, independentemente do conteúdo matemático:

uma atividade matemática pode ser bem sucedida se a sua apresentação e seu desenvolvimento não exigir alguma transformação entre as expressões de formulações ou de representações congruentes e, a mesma tarefa matemática dada com uma variante que implique manipulação de dados não congruentes, pode conduzir ao insucesso (2012, p. 110).

\section{Conclusão}

Buscou-se, com o estudo desenvolvido, organizar atividades voltadas para a aprendizagem da estrutura do SND, para serem propostas em situação de ensino. Elencou-se uma teoria de representações semióticas para servir de sustentação teórica e, desse modo, avaliar como contemplar, nessas atividades, as operações cognitivas de formação, tratamento e conversão de registros de representação do número, especificamente, a palavra e o numeral arábico. Igualmente, procurou-se deixar explicitada a maneira de contemplar, nas atividades propostas, tanto o aprendizado do conteúdo dos registros de representação do número como a identificação da estrutura do SND nesses mesmos registros, além das formas de enfrentar o fenômeno não congruência semântica, atendendo a procedimentos metodológicos exigidos.

As especificidades das diferentes operações cognitivas de produção, tratamento e conversão foram explicitadas nas diversas análises realizadas, que se referiam às distintas atividades propostas. As análises e interpretações efetuadas conduziram à explicitação das representações em relação tanto ao que elas representam quanto ao sistema pela qual elas são produzidas. Isso poderá permitir distinguir 
o conteúdo da representação do objeto representado, bem como os diversos tipos de representação de acordo com os objetos ou a semelhança entre o conteúdo da representação e o objeto da representação. Igualmente, admitirá levar em conta as representações produzidas pelo próprio sujeito, que vai depender dos sistemas produtores de representação de que ele dispõe, significando uma diversidade de representações possíveis. Em consequência, o conteúdo da representação de um objeto pode variar consideravelmente segundo o sistema mobilizado para produzir a representação desse objeto. Se esse conteúdo varia, significa que as propriedades e as particularidades do objeto podem ser explicitadas de formas diferentes, a depender do sistema de representação mobilizado.

Acredita-se ter apresentado reflexões e análises suficientes para justificar uma abordagem diferenciada, não contemplada nas práticas hegemônicas para conduzir o processo de ensino do SND e nos livros didáticos, mas que são de extrema relevância para a sua conceitualização. Com a proposta das atividades, espera-se tornar possível o enfrentamento de problemas colocados pela não congruência existente entre os dois tipos de registros de representação: a escrita e o numeral arábico.

\section{Some considerations on the teaching of the number system: discussion of activities in light of the conceptualization and semiotic representation}

\section{Abstract}

This paper presents reflections about the process of teaching and learning the structure of the decimal number system present in records of number representation. Records in the form of Arabic numerals and words were considered. The study aimed at understanding the attribution of meaning to the reserves in operations and the identification of the relative value of the representation of Arabic numerals, which depends on the position occupied by the digit in the numeral. Another aim of the study was to understand the relation between numbers as groups of powers of ten, according to the position in the numeral, and the suffixes and prefixes as groups of powers of ten in the word. The theoretical support of the study is based on the notion of non-matching semantics and in the treatment operations and conversion within the theory of records of semiotic representation developed by R. Duval.

Keywords: Decimal number system. Records of semiotic representation. Representation versus conceptualization. 


\section{Nota}

1 Em Brandt (2005), pode ser encontrada a análise da congruência semântica entre registros de representação de números naturais compreendidos no intervalo de 0 a 100.

\section{Referências}

BRANDT, C. F. Contribuições dos registros de representação semiótica na conceituação do sistema de numeração. 2005. Tese (Doutorado em Educação Científica e Tecnológica) - Universidade Federal de Santa Catarina, Florianópolis, 2005.

DUVAL, R. Sémiósis et pensée humaine: registres sémiotiques et apprentissages intellectuels. Suisse: Peter Lang, 1995.

. Quel cognitive retenir em didactique des mathématiques? Recherches em didactique des mathématiques. La pensée Sauvage, v. 16, n. 48, p. 349-380, 1996.

Registros de representação semióticas e funcionamento cognitivo da compreensão em matemática. In: MACHADO, S. D. A. (Org.). Aprendizagem em matemática: registros de representação semiótica. Campinas, SP: Papirus, 2003a. p. 11-33.

Decrire, visualizer ou raisonner: quels "aprentissages premiers" de l'activité mathématique? In: IREM - DIDACTIQUE ET DE SCIENCES COGNITIVES, 8, Strasbourg, Anais... Strasbourg, 2003b. p. 13-62. SERÁ QUE NÃO HOUVE UMA INVERSÃO DAS CITAÇÕES COM ESTA OBRA?

Diferenças semânticas e coerência matemática: introdução aos problemas de congruência. Trad. de Méricles Thadeu Moretti. REVEMAT - Revista Eletrônica de Educação Matemática, Florianópolis: UFSC/MTM/PPGECT, v. 7, n. 1, p. 97-117, 2012. Disponível em <www.periodicos. ufsc.br/index.php/revemat>. Acesso em: 18 jan. 2012.

FUSON, K. C.; KWON, Y. Systèmes de mots-nombres et outres outils culturels: effets sur les premiers calculs de l'enfant. In: BIDEAU, J.; MELJAC, C.; FISCHER, J. P. Les chemins du nombre. França: Presses Universitaires de Lille, 1991. p. 351-374.

KAMII, C.; JOSEPH, L. L. Aritmética: novas perspectivas implicações da teoria de Piaget. São Paulo: Papirus, 1992.

.; LIVINGSTON, S. J. Desvendando a aritmética: implicações da teoria de Piaget. São Paulo: Papirus, 1995.

.; DECLARK, G. Reinventando a aritmética: implicações da teoria de Piaget. 11. ed. Campinas, SP: Papirus, 1996.

LERNER, D.; SADOVSKY, P. O sistema de numeração: um problema didático. In: SAIZ, I.; PARRA, C. Didática da matemática: reflexões psicopedagógicas. Porto Alegre: Artmed, 1996. p. 73-154.

TEIXEIRA, L. R. M. Aprendizagem inicial do valor posicional dos números: conceituação e simbolização. In: NOVAES, M.H. e BRITO, M. R. F. (Orgs.). Psicologia na educação: articulação entre pesquisa, formação e prática pedagógica. Rio de Janeiro: Associação Nacional de Pesquisa e Pós-Graduação e Psicologia, 1996. p. 187-204. (Coletâneas da ANPEPP). 